\title{
Hemicorporectomia associada à colostomia úmida. Procedimento de exceção
}

\section{Hemicorporectomy with double barreled wet colostomy - an extremely rare procedure}

\author{
Marco Antonio Ricci 1; Ênio lucio Coelho Duarte ${ }^{\text {; }}$ Renato Costa Amaral Souza ${ }^{1}$; Carlos Michel Albuquerque-Peres ${ }^{1}$; \\ Gustavo Cardoso Guimaraes, TCBC-SP 2; Ademar Lopes, TCBC-SP ${ }^{3}$
}

\section{R E S U M O}

\begin{abstract}
Por ser um procedimento de alta complexidade, a Hemicorporectomia associada a Colostomia úmida em alça deve ser empregada como procedimento de exceção. Por ser uma medida heróica trata-se do último recurso utilizado para tratamento de doenças pélvicas localmente avançadas e sem evidências de metástases à distância.

Analisamos retrospectivamente os detalhes da técnica cirúrgica utilizada em um caso de carcinoma epidermóide desenvolvido em ulcera de pressão de região sacra e os resultados da primeira Hemicorporectomia associada a colostomia úmida em alça em um único tempo.
\end{abstract}

Descritores: Carcinoma de células escamosas. Neoplasias pélvicas. Colostomia.

\section{INTRODUÇÃO}

$\mathrm{O}$ procedimento conhecido como hemicorporectomia foi proposto por Kredel em 1951, e realizado somente após dez anos por Kennedy, porém com óbito pós-operatório. No ano seguinte Aust et al., na Universidade de Minnesota relataram a primeira hemicorporectomia realizada com sucesso, e longa sobrevida, (aprox. 19 anos) ${ }^{1-3}$.

Este é um dos tipos de amputação mais radical e mutiladora existente, portanto devemos atentar que ela nunca deve ser a primeira opção cirúrgica. Vários fatores devem ser considerados antes de se decidir pela amputação translombar, dentre eles: desejo e aceitação do paciente; condições do tumor; condições clínicas; prognóstico e possibilidade de apoio e inclusão social. No caso relatado, um dos maiores benefícios, foi a inclusão social do paciente, visto que sua doença o deixou confinado ao leito e excluído até mesmo do convívio com familiares.

\section{CASO CLÍNICO}

F.C.O., 24 anos, masculino, natural e procedente de Oriximiná, Pará, internado em Junho de 2006 na Fundação Centro de Controle Oncológico do Amazonas, com carcinoma epidermóide bem diferenciado na região glútea e sacra, desenvolvido em úlcera de pressão, como sequela de paraplegia congênita, devido à mielomeningocele, com evolução de aproximadamente dois anos, com extensão para região perianal e perineal, e tecido adiposo subjacente. Observavam-se múltiplas cicatrizes, correspondentes a úlceras anteriores nas zonas de contato dos trocanteres maiores e cristas ilíacas. (Figura 1a)

Além das ulcerações de pressão, o paciente apresentava infecções de repetição no local, e dor de intensidade crescente. O estadiamento com tomografia computadorizada de tórax abdome e pelve e ressonância magnética de pélvis, descartou a presença de metástase à distância, e a hemicorporectomia foi proposta e aceita pelo paciente e sua família. (Figura 1b) Na admissão o paciente encontrava-se com infecção localizada nos locais das úlceras, com forte odor e drenando secreção purulenta. (Figuras 1 c e $1 d$ )

\section{Descrição da Técnica}

O procedimento teve duração de $13 \mathrm{~h}$, realizado em estágio único. Foi utilizada incisão transversa anterior, $7 \mathrm{~cm}$ abaixo do umbigo estendendo-se de um flanco ao outro, até exposição da cavidade. O inventário da cavidade não revelou tumoração intra-abdominal ou envolvimento visceral. As alças intestinais foram rebatidas superiormente (manobras de CATTELL e Mattox) e o espaço retroperitonial foi acessado. A aorta foi ligada, imediatamente acima da bifurcação das artérias ilíacas,

Trabalho realizado no Departmento de Cirurgia Pelvica. Hospital do Câncer, AC Camargo, São Paulo-SP-BR.

1. Cirurgião Oncologista do Departamento de cirurgia Abdomino-Pélvica. Fundação CECON, Manaus, Amazônia-BR. 2. Mestre em Oncologia do Departamento de Cirurgia Pelvica. Hospital do Câncer, AC Camargo, São Paulo-SP-BR. 3. Livre Docente em Oncologia do Departmento de Cirurgia Pelvica. Hospital do Câncer, AC Camargo, São Paulo-SP-BR. 


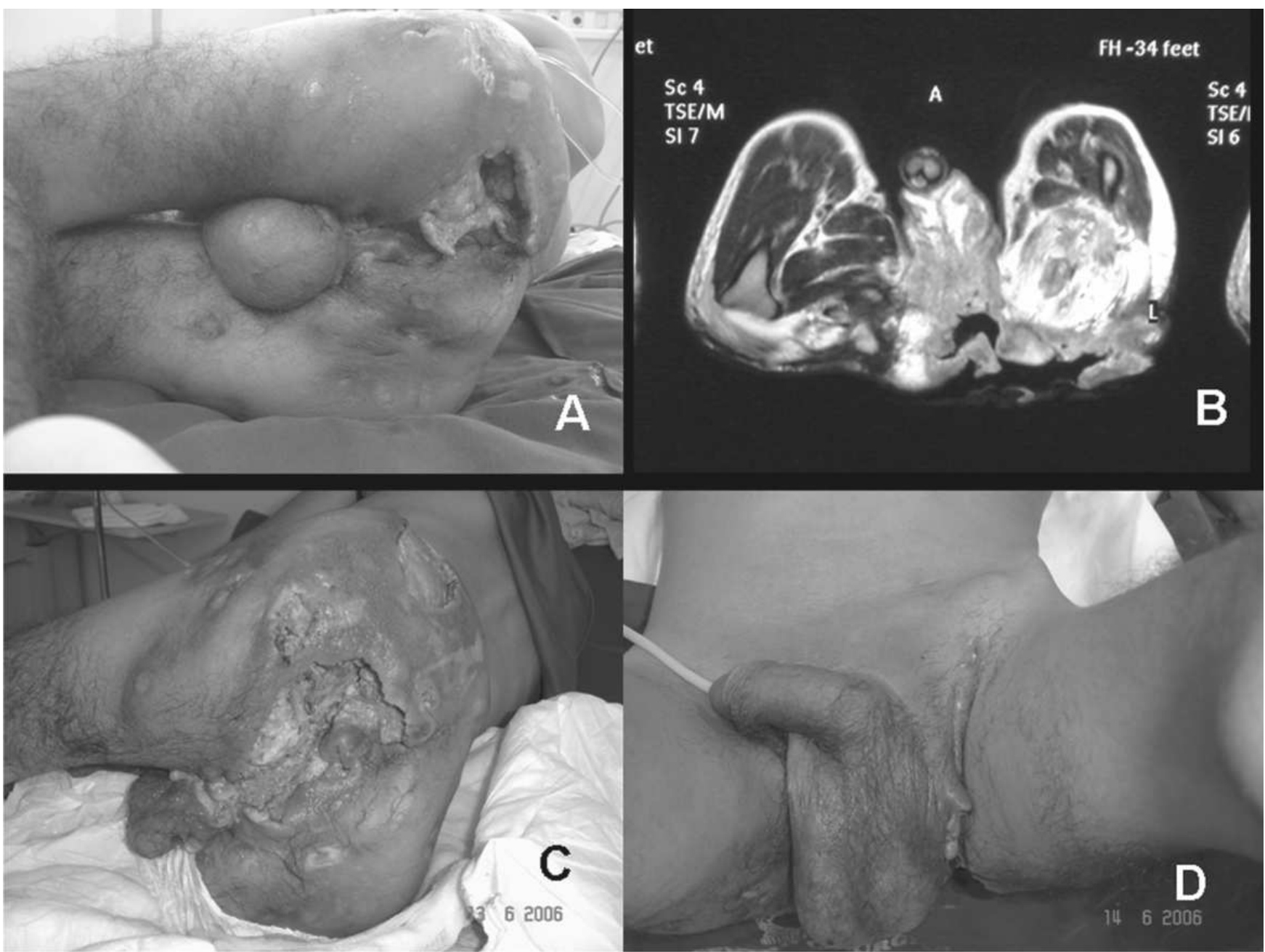

Figura 1 - $\quad \boldsymbol{A}$ - Úlceras de escara nas zonas de contato dos trocanteres maiores e cristas ilíacas. B - Ressonância da pelve mostrando grande comprometimento local. C - Aspecto do hemicorpo amputado e D - Úlceras, com forte odor e drenando secreção purulenta, com linfadenomegalia inguinal esquerda.

com sutura transfixante dupla com polipropileno 3-0 e a veia cava foi ligada com fio de polipropileno 4-0 com sutura contínua. Os ramos vertebrais da aorta e tributárias da veia cava próximos a terceira vértebra lombar foram ligados (nível da amputação).

A exposição das vértebras L3 e L4 (nível da amputação) não apresentou dificuldades. Porém o fato do paciente ser portador de uma mal-formação congênita revelou-se um desafio, visto que a herniação da medula, deuIhe um aspecto de gancho, tornando-a uma "âncora" e seu descolamento tornou-se impossível. Foi realizada corpectomia de L4, evidenciando tecido medular displásico (neste nível deveria haver cauda eqüina, porém nas mielomeningoceles, frequentemente a medula está "ancorada" nos níveis sacrais (tethered cord). Em seguida foi realizada a transecção medular, seguida de osteotomia dos pedículos da vértebra $L 4$ e dos resíduos de suas lâminas bilateralmente. $\mathrm{O}$ saco dural foi suturado em fundo cego com polipropileno 5-0. Os ureteres foram seccionados no seu terço médio e cateterizados para uma bolsa coletora para controle da diurese.

Realizada hemicolectomia esquerda com confecção de colostomia úmida em alça (Figura 2a). Cada ureter foi implantado em uma tênia anti-mesentérica diferente do segmento distal do cólon. A colostomia úmida consiste na elaboração de um estoma a partir do cólon, onde a boca proximal se destina à eliminação de fezes e a boca distal à eliminação de urina. Sua exteriorização foi colocada no hipocôndrio direito (Figuras 2b).

Após a retirada do hemicorpo amputado (Figura 2c) deu-se o fechamento da cavidade abdominal. A confecção de retalho miocutâneo a partir da face ântero-lateral da coxa, não foi realizado, pois a parede anterior apresentava boa mobilidade sendo realizada a aproximação primaria com a parede posterior, utilizando-se fios de nylon 0 com pontos separados. A aproximação do subcutâneo com fio absorvível e síntese da pele com pontos separados de nylon 4-0. O estudo anatomopatológico do espécime cirúrgico confirmou tratar-se de carcinoma epidermóide de área de pressão cutânea com envolvimento de reto, bexiga e próstata e do sacro.

\section{Período pós-operatório}

O paciente permaneceu as primeiras $48 \mathrm{~h}$ em regime de terapia intensiva. Durante este período não apresentou alterações hemodinâmicas significativas ou altera- 
ções respiratórias, sendo retirado da ventilação mecânica 8h após o término do procedimento.

O paciente manteve íleo adinâmico com vômitos ate $\circ 2^{\circ} \mathrm{PO}$ e distensão abdominal persistente até o $5^{\circ} \mathrm{PO}$ devido à hipopotassemia de difícil controle. A principal complicação foi a dor pós-operatória importante que não cedeu com analgésicos comuns, fato que colaborou para a persistência do íleo adinâmico e dos vômitos. O controle da dor com sucesso se deu com o uso transdérmico de opióides (fentanil 50 $\mu \mathrm{g}$ ), e associação com amitriptilina $25 \mathrm{mg}$ via oral uma vez ao dia. O paciente fez uso de antibioticoterapia por 14 dias com ceftriaxona e metronidazol.

O paciente não apresentou complicações descritas ${ }^{1}$ como hipertermia, alterações metabólicas, nem comprometimento respiratório por edema agudo, ou por diminuição da complacência pulmonar. Não ocorreu infecção de ferida operatória nem sinais de irritação meníngea recebendo alta no $14^{\circ}$ pós-operatório.

O paciente realizou fisioterapia motora, para facilitar sua mobilidade e fortalecer a musculatura dos membros superiores e iniciou reposição hormonal com testosterona. Em um ano e oito meses de acompanhamento não apresenta dores fantasma, nem dependência de opióides, ou sinais de recidiva. Atualmente encontra-se inserido no mercado de trabalho e apresenta vida social. Apresenta movimentação com o uso dos membros superiores e uma cadeira de rodas foi adaptada base de sustentação para facilitar o apoio ao corpo, permitindo maior facilidade de movimentação.

\section{DISCUSSÃO}

O procedimento proposto é uma medida radical e heróica, que deve ser muito bem avaliado pela equipe cirúrgica, e intensamente discutido com o paciente e seus familiares. As poucas publicações sobre o assunto, limitam a técnica cirúrgica, mas elucidam suas indicações ${ }^{1-7}$. Vários autores preconizam a realização da hemicorporectomia em dois estágios ${ }^{1-4}$ sendo o primeiro estágio para construção da colostomia, da bolsa ileal, e para o estadiamento da doença, e melhora nutricional do paciente além da diminuição do segundo tempo cirúrgico. Neste caso optou-se


Figura 2 - $\quad \boldsymbol{A}$ - Representação esquemática da colostomia úmida em alça. B - Aspecto final do posicionamento da colostomia úmida em alça. C - e D - Aspecto tardio do paciente já em processo de reabilitação. 
pela realização da hemicorporectomia em um único estágio, pois o paciente apresentava uma extensa infecção do períneo, de difícil controle medicamentoso e cirúrgico. Outra opção adotada foi a construção de um único estoma destinada a eliminação de fezes e urina, baseada em publicações recentes ${ }^{6}$ que demonstra o funcionamento adequado, maior conveniência para o paciente, redução de custo na manutenção do estoma e, também redução no tempo total de cirurgia.

O manejo de líquidos para o paciente foi realizado com extrema cautela, pois sabe-se que a redução abrupta da massa corpórea leva à hipervolemia, podendo causar edema agudo de pulmão, edema cerebral e consequentemente hipertensão intracraniana.

A dificuldade do controle da dor talvez tenha se ocasionado pela secção mais alta da medula (envolvendo o cone medula) e das raízes que compunham a cauda eqüina ${ }^{2,4}$ devido ao defeito que a mesma apresentava. Porém o adequado manejo durante o acompanhamento ambulatorial permitiu a retirada escalonada dos opióides, antidepressivos tricíclicos, e analgésicos comuns, estando o paciente livre de quaisquer medições para dor.

Um procedimento extremo como este somente deve ser aventado como possibilidade terapêutica quando houver a possibilidade de reinclusão social, com suporte psicológico e fisioterápico. O grande benefício do procedimento foi a possibilidade de inclusão social trazida ao paciente, (Figura 2d). Atualmente o paciente encontra-se no mercado de trabalho como digitador, tem maior facilidade de movimentação, com reinclusão social compatível em melhores condições do que apresentava antes do procedimento.

\title{
A B S T R A C T
}

\begin{abstract}
The Hemicorporectomy associated to Double-barreled wet colostomy is a high complex and heroic procedure and is to be used only exceptionally, when it is the last resource for treating locally advanced pelvic diseases in the absence of evidences of distant metastasis. We retrospectively analyzed the surgical technical details and the results from a hemicorporectomy with double-barreled wet colostomy in a single surgical time in a case of epidermoide carcinoma from a coetaneous pressure ulcer.
\end{abstract}

Key words: Carcinoma, squamous cell. Pelvic neoplasms. Colostomy.

\section{REFERÊNCIAS}

1. Weaver JM, Flynn MB. Hemicoporectomy. J Surg Oncol. 2000; 73(2):117-24.

2. Ferrara BE. Hemicorporectomy: a collective review. J Surg Oncol. 1990; 45(4):270-8

3. Porter-Romatowski TL, Deckert J. Hemicorporectomy: a case study from a physical therapy perspective. Arch Phys Med Rehabil. 1998; 79(4):464-8.

4. Pearlman NW, McShane RH, Jochimsen PR, Shirazi SS. Hemicorporectomy for intractable decubitus ulcers. Arch Surg. 1976; 111(10):1139-43.

5. Alam M, Ratner D. Cutaneous squamous-cell carcinoma. N Engl J Med. 2001; 344(13): 975-83.

6. Guimaraes GC, Ferreira FO, Rossi BM, Aguiar S Jr, Zequi SC, Bachega $W$ et al. Double-barreled wet colostomy is a safe option for simultaneous urinary and fecal diversion. Analysis of 56 procedures from a single institution. J Surg Oncol. 2006; 93(3): 206-11.
7. Chang DW, Lee JE, Gokaslan ZL, Robb GL. Closure of hemicorporectomy with bilateral subtotal thigh flaps. Plast Reconstr Surg. 2000; 105(5):1742-6.

Recebido em 20/02/2009

Aceito para publicação em 23/04/2009

Conflito de interesse:

Fonte de financiamento: nenhuma

\section{Como citar este artigo:}

Ricci MA, Duarte ELC, Souza RCA, Peres CMA, Guimarães GC, Lopes A. Hemicorporectomia associada à colostomia úmida. Procedimento de exceção.. Rev Col Bras Cir. [periódico na Internet] 2009; 36(6). Disponível em URL: http://www.scielo.br/rcbc

\section{Endereço para correspondência:}

Gustavo Cardoso Guimarães

E-mail: guimaraesgc@uol.com.br, guimaraesgc@gmail.com 